\title{
Specific Temporal Distribution and Subcellular Localization of a Functional Vesicular Nucleotide Transporter (VNUT) in Cerebellar Granule Neurons
}

\section{OPEN ACCESS}

Edited by:

Francisco Ciruela

University of Barcelona, Spain

Reviewed by:

Marçal Pastor-Anglada

University of Barcelona, Spain

Arun Chaudhury,

GIM Foundation, United States

${ }^{*}$ Correspondence: Rosa Gómez-Villafuertes marosa@ucm.es; marosa@vet.ucm.es

María T. Miras-Portugal mtmiras@ucm.es; mtmiras@vet.ucm.es

Specialty section:

This article was submitted to Experimental Pharmacology and Drug

Discovery,

a section of the journal

Frontiers in Pharmacology

Received: 25 October 2017 Accepted: 15 December 2017

Published: 22 December 2017

Citation:

Menéndez-Méndez A, Díaz-Hernández Jl, Ortega F Gualix J, Gómez-Villafuertes $R$ and Miras-Portugal MT (2017) Specific Temporal Distribution and Subcellular Localization of a Functional Vesicular Nucleotide Transporter NNUT) in Cerebellar Granule Neurons. Front. Pharmacol. 8:951. doi: 10.3389/fphar.2017.00951

\begin{abstract}
Aida Menéndez-Méndez"1,2,3, Juan I. Díaz-Hernández',2,3, Felipe Ortega 1,2,3, Javier Gualix ${ }^{1,2,3}$, Rosa Gómez-Villafuertes ${ }^{1,2,3 *}$ and María T. Miras-Portugal1,2,3*

${ }^{1}$ Department of Biochemistry and Molecular Biology, Faculty of Veterinary, Complutense University of Madrid, Madrid, Spain ${ }^{2}$ University Institute of Neurochemistry Research (IUIN), Complutense University of Madrid, Madrid, Spain, ${ }^{3}$ Instituto de Investigación Sanitaria del Hospital Clínico San Carlos, Madrid, Spain
\end{abstract}

Adenosine triphosphate (ATP) is an important extracellular neurotransmitter that participates in several critical processes like cell differentiation, neuroprotection or axon guidance. Prior to its exocytosis, ATP must be stored in secretory vesicles, a process that is mediated by the Vesicular Nucleotide Transporter (VNUT). This transporter has been identified as the product of the SLC17A9 gene and it is prominently expressed in discrete brain areas, including the cerebellum. The main population of cerebellar neurons, the glutamatergic granule neurons, depends on purinergic signaling to trigger neuroprotective responses. However, while nucleotide receptors like P2X7 and P2Y13 are known to be involved in neuroprotection, the mechanisms that regulate ATP release in relation to such events are less clearly understood. In this work, we demonstrate that cerebellar granule cells express a functional VNUT that is involved in the regulation of ATP exocytosis. Numerous vesicles loaded with this nucleotide can be detected in these granule cells and are staining by the fluorescent ATP-marker, quinacrine. High potassium stimulation reduces quinacrine fluorescence in granule cells, indicating they release ATP via calcium dependent exocytosis. Specific subcellular markers were used to assess the localization of VNUT in granule cells, and the transporter was detected in both the axonal and somatodendritic compartments, most predominantly in the latter. However, co-localization with the specific lysosomal marker LAMP-1 indicated that VNUT can also be found in non-synaptic vesicles, such as lysosomes. Interestingly, the weak co-localization between VNUT and VGLUT1 suggests that the ATP and glutamate vesicle pools are segregated, as also observed in the cerebellar cortex. During postnatal cerebellar development, VNUT is found in granule cell precursors, co-localizing with markers of immature cells like doublecortin, suggesting that this transporter may be implicated in the initial stages of granule cell development.

Keywords: VNUT, granule cells, cerebellum, ATP exocytosis, VGLUT1, GCPs 


\section{INTRODUCTION}

Extracellular adenosine triphosphate (ATP) and nucleotide analogs influence essential activities in the nervous system, acting through both G protein-coupled P2Y receptors and ionotropic P2X receptors (for review see (Burnstock, 2006, 2013). ATP is mainly released from neural cells by an exocytotic process (Gutierrez-Martin et al., 2011), which requires a previous storage into secretory vesicles (SVs), a process mediated by a specific vesicular transporter. Depending on the cell type and the environmental conditions, ATP release may also be driven by connexins and pannexins, large-pore ion and metabolite channels (for review see (Baroja-Mazo et al., 2013).

Vesicular neurotransmitter transporters (VNTs) drive the storage of specific soluble compounds in SVs, a crucial step in neurotransmission. Vesicles containing more than one neurotransmitter require specific VNTs for each of them. The abundance of ATP in secretory granules opens new horizons in neurotransmission and the term co-transmission was coined by Burnstock $(1976,2004) 40$ years ago in reference to such complexity. Initially, the storage of different nucleotides in the same catecholaminergic chromaffin granules was reported, and then further confirmed in cholinergic and other storage vesicles (reviewed by Winkler and Westhead, 1980; Volknandt and Zimmermann, 1986). The vesicular monoamine transporter (VMAT1) was the first VNT to be isolated from a rat leukemia cell line cDNA library (Erickson et al., 1992). The existence of an active vesicular nucleotide transporter (VNUT) was first inferred from its kinetic parameters, exhibiting a mnemonic saturation profile and low specificity, capable of transporting a variety of nucleotides at intravesicular concentrations close to $150 \mathrm{mM}$ (Bankston and Guidotti, 1996; Gualix et al., 1996, 1999a). The VNUT was identified as a product of the SLC17A9 gene (Sawada et al., 2008), a member of the anion solute carrier transporters 17 family (SLC17) that includes other VNTs, such as the three vesicular glutamate transporter isoforms (VGLUT1, VGLUT2 and VGLUT3). Recently, the role of VNUT has been studied extensively in chromaffin granules from the adrenal medulla, assessing catecholamine storage and granule release (EstevezHerrera et al., 2016). Moreover, co-localization of VNUT and the vesicular acetylcholine transporter (VAChT) has been reported in cholinergic vesicles from the electroplaque of Torpedo californica (Li and Harlow, 2014), and in other types of secretory granules (Haanes and Novak, 2010).

Immunohistochemical studies in the brain have demonstrated that VNUT is not homogeneously expressed in all cell subtypes and anatomical structures, rather it is particularly abundant in the mouse cerebellar cortex (Larsson et al., 2012). Among the different cell populations that constitute the cerebellum, granule neurons in the granular layer of adults is the most numerous cell subtype. Cerebellar granule neurons are glutamatergic cells that express high levels of VGLUT1 (Hallberg et al., 2006). The axons from these neurons ascend to the molecular layer, where they bifurcate to form the parallel fibers that connect with the dendritic tree of Purkinje cells (Ramón y Cajal, 1889, 1904, 1995; Cerminara et al., 2015). Primary cultures of cerebellar granule neurons are widely used to study neurotransmission, as these cells can develop the morphological, biochemical and electrophysiological characteristics of mature neurons in vitro. Indeed, they express a variety of functional P2Y and P2X nucleotide receptors, making them a suitable model to study the purinergic system (Hervas et al., 2003, 2005; Leon et al., 2006; Sanchez-Nogueiro et al., 2009, 2014).

The maturation of granule cells in culture is accompanied by time-dependent changes in the expression and activity of purinergic receptors (Sanz et al., 1996; Hervas et al., 2003). We previously reported that activation of either P2X3 or P2X7 receptors induces an increase in cytosolic $\mathrm{Ca}^{2+}$ in cerebellar granule neurons, resulting in the exocytotic release of glutamate and the subsequent enhancement of synapsin-1 phosphorylation (Leon et al., 2006, 2008). In addition, both the $\mathrm{P}_{2} \mathrm{Y}_{13}$ and $\mathrm{P} 2 \mathrm{X} 7$ receptors in granule neurons are involved in neuroprotection (Ortega et al., 2009; Ortega et al., 2010, 2011; Morente et al., 2014; Miras-Portugal et al., 2016). Despite the obvious importance of the purinergic system in the pathophysiological context of granule cells, there is currently no information concerning vesicular ATP storage and its relationship with VNUT expression. Moreover, granule neuron development occurs in the context of the cerebellar structure, and thus, it would be relevant to study the presence and evolution of VNUT in a more physiological context.

In the present work, we analyzed the vesicular release of ATP from primary cultures of cerebellar granule cells, studying the involvement of VNUT in this process and the effect of its inhibition. The distribution of VNUT was compared to that of VGLUT1 in vitro and in vivo, assessing both the subcellular location and temporal evolution during neuronal maturation. Our findings shed light on the ATPergic and glutamatergic nature of cerebellar granule neurons.

\section{MATERIALS AND METHODS}

\section{Ethics Statement}

All animal procedures were carried out at the Complutense University of Madrid in accordance with European and Spanish regulations (2010/63/EU; RD1201/2005; RD 53/2013), and following the guidelines of the International Council for the Laboratory Animal Science. The C57BL/6 mice used in these studies were obtained in-house. The protocols employed were approved by the Committee for Animal Experiments at the Complutense University of Madrid and by the Committee for Animal Ethics of the Regional Government of Madrid.

\section{Cerebellar Granule Cells Culture}

Primary cultures of cerebellar granule cells were prepared using a modified version of the procedure described by Pons et al. (2001). Briefly, the cerebellum was dissected out from postnatal day 5 mice and dissociated with the Papain Dissociation System (Worthington Biochemical, Lakewood, NJ, United States). Neurons were plated onto coverslips at a density of $120,000 \mathrm{cells} / \mathrm{cm}^{2}$ or in culture plates pre-coated with polyL-lysine (10 $\mu \mathrm{g} / \mathrm{ml}$; Biochrom, Berlin, Germany) and they were maintained at $37^{\circ} \mathrm{C}$ in a humidified atmosphere containing $5 \% \mathrm{CO}_{2}$ and in Neurobasal medium (Life Technologies, 
Gaithersburg, MD, United States) supplemented with 2\% B27, $25 \mathrm{mM} \mathrm{KCl}, 1 \%$ GlutaMAX $^{\mathrm{TM}}, 100 \mathrm{U} / \mathrm{ml}$ penicillin and 0.1 $\mathrm{mg} / \mathrm{ml}$ streptomycin. The antimitotic drug cytosine arabinoside (AraC, $10 \mu \mathrm{M}$ ) was added to the culture medium to avoid the proliferation of non-neuronal cells.

\section{RT-PCR and Quantitative Real-Time PCR}

Total RNA was obtained from cultured granule cells using a SpeedTools Total RNA Extraction kit (Biotools), following the manufacturer's instructions. After purification, the total RNA was quantified and $1 \mu \mathrm{g}$ was reversed transcribed using M-MLV reverse transcriptase, $6 \mu \mathrm{g}$ of random primers and $350 \mu \mathrm{M}$ dNTPs (all from Thermo Fisher Scientific). Quantitative realtime PCR (qPCR) reactions were performed in final volume of $25 \mu l$ using the LuminoCt qPCR Ready Mix (Sigma-Aldrich), $5 \mu \mathrm{l}$ of the cDNA synthesized previously and $1.25 \mu \mathrm{l}$ of specific commercial TaqMan ${ }^{\circledR}$ gene expression assays for mouse: VGLUT1 (Mm00812886_m1), VNUT (Mm00805914_m1), the housekeeping gene glyceraldehyde 3-phospate dehydrogenase (GAPDH, Mm99999915_g1), all from Applied Biosystems. The qPCR assays were carried out using a StepOnePlus Real-Time PCR System (Applied Biosystems) as follows: denaturation at $95^{\circ} \mathrm{C}$ for $20 \mathrm{~s}$, followed by 40 cycles of $95^{\circ} \mathrm{C}$ for $1 \mathrm{~s}$ and $60^{\circ} \mathrm{C}$ for $20 \mathrm{~s}$. As indicated, the expression of each gene was normalized to that of the endogenous housekeeping gene GAPDH amplified in parallel.

\section{Western Blotting}

Granule cells or cerebellar tissues were lysed and homogenized for $1 \mathrm{~h}$ at $4^{\circ} \mathrm{C}$ in lysis buffer ( $\left.\mathrm{pH} 7.4\right)$ containing $50 \mathrm{mM}$ Tris$\mathrm{HCl}, 150 \mathrm{mM} \mathrm{NaCl}, 1 \%$ Nonidet P40 and Complete ${ }^{\mathrm{TM}}$ Protease Inhibitor Cocktail Tablets (Roche Diagnostics $\mathrm{GmbH}$ ). The cell lysate was then centrifuged at $16,000 \times \mathrm{g}$ for $9 \mathrm{~min}$ and the supernatants collected. Protein extracts were resolved on $10 \%$ SDS-PAGE gels and transferred to nitrocellulose membranes, which were then blocked for $1 \mathrm{~h}$ at RT $\left(\sim 25^{\circ} \mathrm{C}\right)$ with $3 \%$ BSA in TBS (10 mM Tris, $137 \mathrm{mM} \mathrm{NaCl,} 2.7 \mathrm{mM} \mathrm{KCl}, 5$ $\mathrm{mM} \mathrm{Na}_{2} \mathrm{HPO}_{4}, 1.4 \mathrm{mM} \mathrm{KH} \mathrm{PO}_{4}$ and $0.1 \%$ Tween [pH 7.5]). The membranes were probed with primary antibodies raised against VNUT (1:500, MBL), anti-VGLUT1 (1:7500, Synaptic Systems) and GAPDH (1:10,000, Sigma Aldrich). Antibody binding was detected by ECL chemiluminescence (Amersham GE Healthcare), and images were captured with ImageQuant LAS 500 (GE Healthcare Life Sciences) and analyzed using ImageQuant TL.

\section{Immunofluorescence}

Granule cells cultured on coverslips in $35 \mathrm{~mm}$ dishes were fixed for 15 min with $4 \%$ paraformaldehyde (PFA) and then rinsed with PBS twice for $10 \mathrm{~min}$. For immunofluorescence studies of the cerebellum, the extracted brains were fixed in $4 \%$ PFA for $24 \mathrm{~h}$, cryoprotected in $30 \%$ sucrose, embedded in O.C.T. (Sakura Finetek), and cryosections $(30 \mu \mathrm{M})$ were obtained in the sagittal plane on a Leica CM1950 cryostat. Afterward, coverslips or cryosections were blocked and permeabilized for $1 \mathrm{~h}$ at RT with blocking solution (0.1\% Triton X-100, 5\% FBS and $10 \% \mathrm{BSA}$ in PBS). The coverslips or sections were then incubated overnight at $4^{\circ} \mathrm{C}$ with the corresponding primary antibodies: rabbit anti-VNUT (1:100, MBL), mouse anti- $\beta$ IIItubulin (1:1000, Promega), mouse anti-VGLUT1 (1:500, Synaptic Systems), mouse anti-synaptophysin (1:500, Sigma-Aldrich), chicken anti-MAP2 (1:1000, Abcam), guinea pig anti-DCX (1:500, Millipore), mouse anti-Math1 (1:250, Abcam), mouse anti-LAMP-1 (1:50, ThermoFisher Scientific), and mouse antiSMI 312 (1:500, Abcam). The following day, the cells or sections were washed three times with PBS and incubated with the corresponding fluorescent-tagged secondary antibodies for $1 \mathrm{~h}$ at RT: Alexa fluor $594^{\circledR}$ donkey anti-rabbit, Alexa fluor $488^{\circledR}$ goat anti-mouse, Alexa fluor $647^{\circledR}$ goat anti-mouse (all from Thermo Fisher Scientific), $\mathrm{Cy}^{\mathrm{TM}} 5$ donkey anti-guinea pig, and FITC donkey anti-chicken (both from Jackson ImmunoResearch). The nuclei were counterstained with 4', 6-diamidino-2-phenylindole (DAPI, Thermo Fisher Scientific) and the coverslips or sections were finally mounted on glass slides using FluoroSave ${ }^{\mathrm{TM}}$ Reagent (Calbiochem). When antibodies against VNUT and Math1 were used on cerebellar sections, streptavidin-biotin amplification of the fluorescence signal was used. Images were acquired on a Leica TCS SPE confocal microscope using the 40X and 63X W/IR objectives.

\section{Fluorescent Labeling of Vesicular ATP}

Quinacrine [4-N-(6-chloro-2-methoxyacridin-9-yl)-1-N,1-Ndiethylpentane-1,4-diamine] was used to visualize vesicular ATP, a fluorescent dye widely used to detect ATP-enriched vesicles (Gutierrez-Martin et al., 2011). Quinacrine staining was carried out by incubating granule cells for $15 \mathrm{~min}$ at $37^{\circ} \mathrm{C}$ in Locke's buffer $\left(140 \mathrm{mM} \mathrm{NaCl}, 4.5 \mathrm{mM} \mathrm{KCl}, 2.5 \mathrm{mM} \mathrm{CaCl}_{2}, 1.2 \mathrm{mM}\right.$ $\mathrm{KH}_{2} \mathrm{PO}_{4}, 1.2 \mathrm{mM} \mathrm{MgSO} 4,5.5 \mathrm{mM}$ glucose and $10 \mathrm{mM}$ HEPES [pH 7.4]) containing $4 \mu \mathrm{M}$ quinacrine (Sigma-Aldrich). Timelapse studies were performed with an Olympus IX81 inverted microscope equipped with a 100X, $1.45 \mathrm{NA}$, oil-immersion objective. Images were acquired every $200 \mathrm{~ms}$ with a Hamamatsu C9100 EM-CCD digital camera (Hamamatsu) controlled by CellR software (Olympus). Vesicular fusion and release into the extracellular space was observed as a rapid loss of the quinacrine signal. During the assays, cells were continuously perfused with Locke's buffer at a rate of $1.5 \mathrm{ml} / \mathrm{min}$ at $37^{\circ} \mathrm{C}$. Perfusion was gravity-driven and solution exchange was performed by manually operating electronic valves of a VC-6 drug application system (Warner Instruments). Images were processed using the ImageJ free software v.1.50i (National Institutes of Health, Bethesda, MD, United States).

\section{ATP Release}

Adenosine triphosphate release was measured using the ENLITEN $^{\circledR}$ rLuciferase/Luciferin reagent (Promega). Granule cells were maintained for $30 \mathrm{~min}$ at $37^{\circ} \mathrm{C}$ in $\mathrm{Mg}^{2+}$-free Locke's buffer containing $100 \mu \mathrm{M}$ ARL67156, a competitive inhibitor of ecto-ATPases (Levesque et al., 2007), and subsequently, $50 \mu \mathrm{l}$ of extracellular medium was collected to measure the basal ATP levels. The cells were then stimulated with $10 \mu \mathrm{M}$ ionomycin and after $5 \mathrm{~min}, 50 \mu \mathrm{l}$ of the extracellular medium was collected to measure ATP concentration after stimulation. The samples were centrifuged at $600 \times g$ for $5 \mathrm{~min}$ at $4^{\circ} \mathrm{C}$ 
and $10 \mu \mathrm{l}$ of supernatant were transferred onto 96-well plate placed on ice. When indicated, cells were incubated with $2 \mu \mathrm{M}$ Evans Blue (Sigma-Aldrich) for $1 \mathrm{~h}$ (Loiola and Ventura, 2011). The plate was then situated in a FLUOstar OPTIMA Microplate Luminometer (BMG LABTECH GmbH) and $100 \mu \mathrm{l}$ of rLuciferase/Luciferin reagent was automatically injected into each well at RT. The ATP concentration was estimated by interpolation from a linear standard curve.

\section{Statistical Analysis}

The data shown are mean values \pm standard error of the mean (s.e.m) and all independent experiments shown were reproduced 3-6 times. The figures were generated and the statistical analyses performed using GraphPad Prism 6 (GraphPad Software). The results were analyzed using an unpaired Student's $t$-tests or ANOVA with Dunnet's Multiple Comparisons test. A $p$-value $\leq 0.05$ was considered statistically significant.

\section{RESULTS}

\section{Cerebellar Granule Cells Express Native Functional VNUT}

The expression of a variety of functional P2Y and P2X nucleotide receptors in primary cultures of cerebellar granule cells was already reported (Hervas et al., 2003, 2005; Leon et al., 2006; Sanchez-Nogueiro et al., 2009, 2014). In order to investigate the presence of native VNUT in granule neurons, western blot and immunofluorescence studies were performed. Unless specified otherwise, all experiments were carried out at day 7 in vitro coinciding with the peak of synaptogenesis in these cultured neurons (Mundy et al., 2008; Juranek et al., 2013). In western blots of total protein extracts from granule cells, a $60 \mathrm{kDa}$ band was detected (Figure 1A) that is consistent with the molecular size of the VNUT protein (Sawada et al., 2008). The specificity of this band was confirmed using specific neutralizing peptides (data not shown). When immunocytofluorescence studies were performed on PFA-fixed cells using antibodies against VNUT and $\beta I I I$-tubulin (Figure 1B), VNUT was widely expressed in granule cells displaying a characteristic punctuate staining of VNTs. The functionality of VNUT was also confirmed through the capacity of granule cells to release ATP in a calciumdependent manner. Using the sensitive luciferin-luciferase assay to quantify ATP in the extracellular medium, the $\mathrm{Ca}^{2+}$ selective ionophore ionomycin produced a significant increase of extracellular ATP relative to the basal unstimulated state (Figure 1C). The kinetics of ATP release reflected a rapid mechanism, completed within seconds of stimulation and suggestive of calcium-dependent exocytosis. The participation of VNUT in vesicular ATP storage was confirmed using Evans Blue, a VNUT inhibitor (Sawada et al., 2008), which reduced the net release of ATP induced by ionomycin (Figure 1C). Remarkably, although Evans Blue was the most effective VNUT inhibitor available, previous studies in synaptic vesicles isolated from rat brain demonstrated that Evans Blue behaved only as a partial inhibitor of ATP release (Gualix et al., 1999b). Likewise, it is important to consider that inhibition of VNUT affects only the subsequent ATP transport and not the ATP stored prior to the treatment, which will be eventually released after ionomycin stimulation. The co-localization of VNUT and the vesicular protein synaptophysin further supported the exocytotic nature of ATP release (Figure 1D). Interestingly, co-localization of VNUT and synaptophysin immunostaining was not complete, indicating that VNUT may also be located in another type of storage vesicle or subcellular structure.

\section{Purinergic Receptor Activation Triggers the Release of ATP-Enriched Vesicles in Granule Cells}

Many neuronal and non-neuronal cells release ATP in a controlled manner. Indeed, an autoregulated mechanism of ATP release has been reported where P2X7 receptor activation not only triggers ATP exocytosis but also, it profoundly modifies secretory vesicle dynamics in $\mathrm{N} 2 \mathrm{a}$ neuroblastoma cells (Gutierrez-Martin et al., 2011). To assess whether similar autoregulation occurs in granule cells, we visualized exocytosis of single ATP-enriched vesicles from granule neurons after activation of purinergic receptors using fluorescence microscopy. Quinacrine is an acidophilic antimalarial drug that binds to intracellular ATP stored in vesicles and that was used as a fluorescent marker to detect the exocytosis of releasable ATP-enriched vesicles (Orriss et al., 2009; Liu et al., 2016). Granule cells contained abundant quinacrine-labeled vesicles and such punctate staining was not only evident throughout the soma but also, in cell prolongations (Figure 2A). Changes in fluorescence of single vesicles were analyzed under basal conditions and during ATP (1 mM) administration (Figure 2B). This ATP concentration was selected in order to trigger $\mathrm{P} 2 \mathrm{X} 7$ receptors, which requires such a high concentration of ATP. As expected, ATP stimulation was followed by a reduction in the number of quinacrine fluorescence puncta (Figure 2B). Moreover, the abrupt time course of fluorescence loss in several regions of interest (ROIs) with quinacrinestained vesicles reflected vesicular fusion with the plasma membrane and quinacrine release into the extracellular medium (Figure 2B). A parallel control assay was performed in which the cells were depolarized with $30 \mathrm{mM} \mathrm{KCl}$, which produced a comparable release of quinacrine-stained vesicles (Figure 2C). These observations demonstrate that ATP-mediated activation of purinergic receptors can induce vesicular ATP release in cerebellar granule neurons.

\section{Subcellular Distribution of the VNUT in Cerebellar Granule Cells}

Given the morphological complexity of cerebellar granule cells in culture, we assessed the co-localization of VNUT with specific subcellular markers to define its distribution. When immunofluorescence was performed with antibodies against the somatodendritic marker microtubule-associated protein 2 (MAP2) and the pan-axonal neurofilament marker (SMI 312), VNUT co-localized with both these subcellular markers, indicating that this vesicular transporter exists both pre- and 

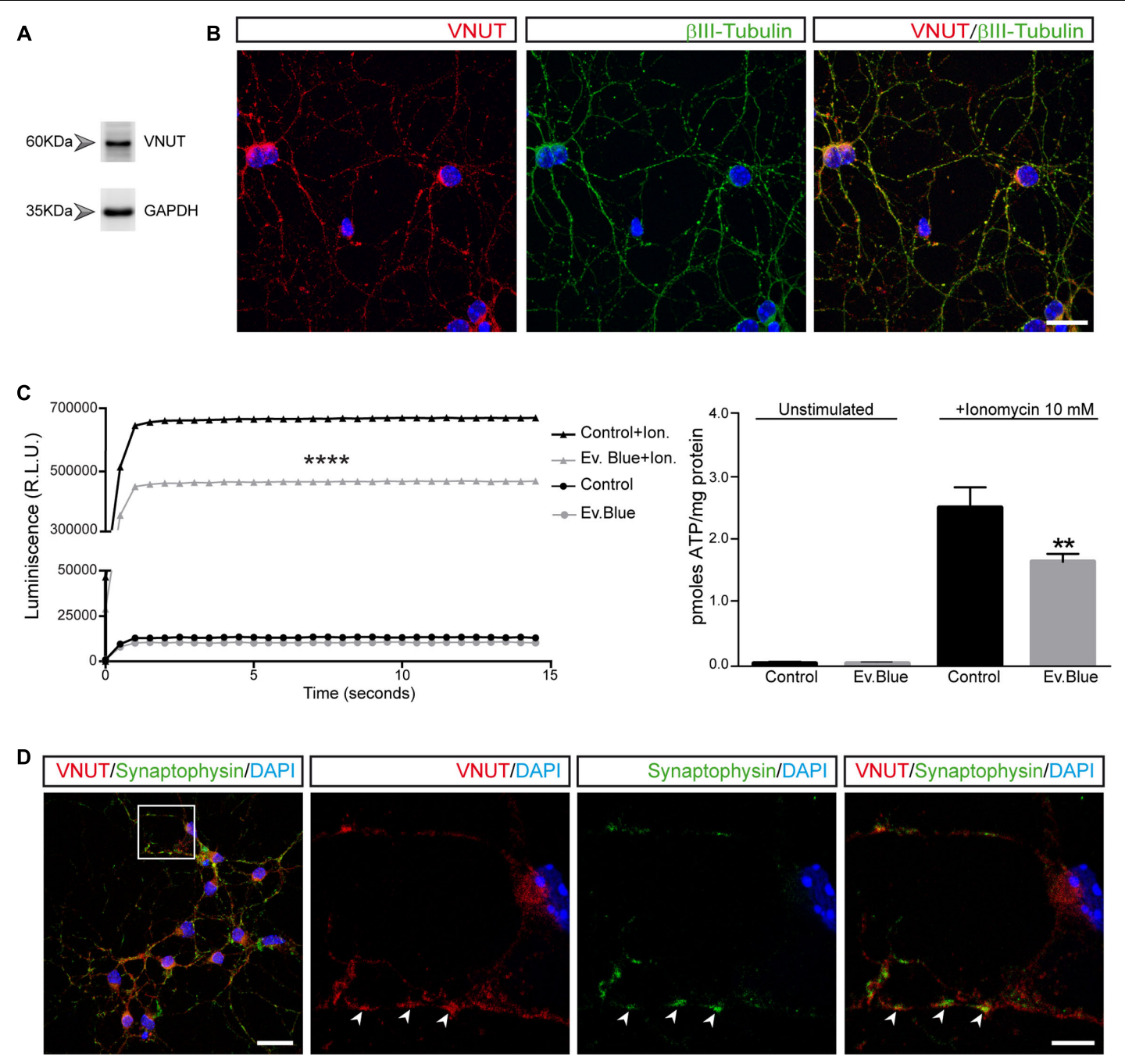

FIGURE 1 | Vesicular nucleotide transporter (VNUT) is expressed by cultured cerebellar granule cells. Identification of VNUT in granule cells by western blotting (A) and immunofluorescence (B). Cells were stained with antibodies against VNUT (red) and Blll-tubulin (green). Scale bar: $20 \mu \mathrm{m}$. (C) ATP release to the extracellular medium by granule cells. The graph shows the luminescence values of cells maintained in the presence or absence of Evans Blue $(2 \mu \mathrm{M})$ and stimulated with ionomycin $(10 \mu \mathrm{M})$ or left unstimulated. The right graph represents the pmoles of ATP released per $\mathrm{mg}$ of protein in the different experimental conditions. The values represent the mean $\pm \operatorname{SEM}\left(n=3:{ }^{* *} p<0.01,{ }^{* * * *} p<0.0001\right.$, unpaired Student's $t$-test). (D) Representative confocal microscopy images of the immunostaining of granule cell neurons for VNUT (red) and synaptophysin (green). The nuclei are counterstained with DAPI (blue). Scale bar: $20 \mu \mathrm{m}$. The inset represents a $4 \mathrm{x}$ magnification of the cell indicated. The arrows indicate the most prominent VNUT and synaptophysin positive vesicles. Scale bar: $5 \mu \mathrm{m}$.

post-synaptically in granule neurons (Figure 3A). However, VNUT co-localized more intensely with MAP-2 than with SMI 312 , suggesting that this vesicular transporter might be more strongly expressed post-synaptically. To confirm the presence of VNUT in dendrites, double immunofluorescence was performed with antibodies against VNUT and the postsynaptic density protein 95 (PSD-95) (Figure 3B). Both these proteins clearly co-localized, confirming that VNUT is located post-synaptically in granule neurons. The abundance of VNUT in the soma of granule cells suggested that this vesicular transporter is actively synthesized and packaged in earlier structures for further subcellular transportation, for instance into storage vesicles. Notably, VNUT expression has previously been reported in lysosomes (Shin et al., 2012; Jung et al., 2013; Oya et al., 2013; Cao et al., 2014) and interestingly, the clear co-localization in certain cytosolic areas of antibody staining for VNUT and the lysosomal marker LAMP-1 (Figure 3C), confirmed the presence of VNUT in lysosomes.

\section{Distribution and Time-Dependent Expression of VNUT and VGLUT1 in Primary Cultures of Cerebellar Granule Neurons}

The glutamatergic phenotype of cerebellar granule cells reflects the storage and release of glutamate as a classic neurotransmitter, which requires the expression of VGLUTs, of which VGLUT1 is the most abundant isoform. Thus, we compared the 


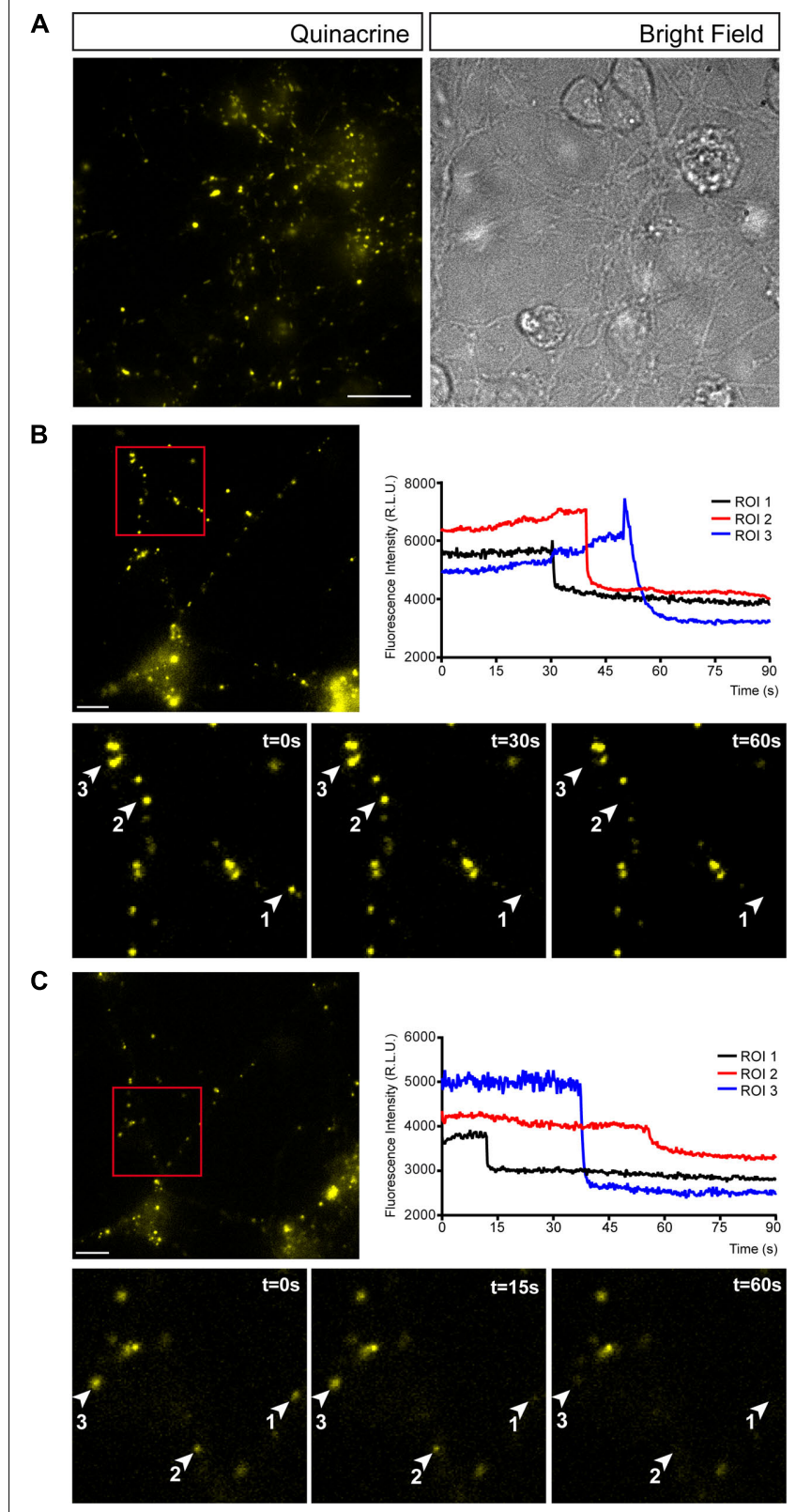

FIGURE 2 | Cerebellar granule cells release ATP through by exocytosis. (A) Representative micrographs of granule cells stained with quinacrine (pseudo colored in yellow). Bright field image of the same area is showed on the right. Vesicular ATP release after stimulation with $1 \mathrm{~mm}$ ATP (B) or $30 \mathrm{mM}$ $\mathrm{KCl}(\mathbf{C})$. In each panel, the upper image corresponds to the micrograph representing quinacrine staining before stimulation. Scale bar: $5 \mu \mathrm{m}$. Insets represent sequential images of quinacrine-loaded vesicles showing the time course of the changes in fluorescence within a ROI during a 60 s stimulation with ATP (B) or $\mathrm{KCl}(\mathbf{C})$. Graphical representation of the changes in fluorescence intensity corresponding to the selected ROls during stimulation with ATP (B) or $\mathrm{KCl}(\mathbf{C})$

subcellular distribution and time-dependent expression of this transporter and VNUT. Interestingly, the dense and abundant co-localization of VNUT and MAP2 was not accompanied by a similar co-localization between VGLUT1 and MAP2, which rarely coincided in dendritic regions (Figure 4). By contrast, while VNUT and SMI 312 co-localized sparsely in some prolongations, the co-localization of staining for SMI 312 and VGLUT1 was dense an almost complete (Figure 4).

Double immunofluorescence was performed to determine whether VNUT and VGLUT1 coincide in the same vesicles and very few vesicles containing VGLUT1 were stained for VNUT, with most expressing only one of these vesicular transporters (Figure 5A). Thus, cerebellar granule cells appeared to contain segregated populations of secretory vesicles that store either ATP or glutamate. However, it should be remembered that these studies were performed in vitro, in primary cultures of granule neurons and, the expression of each transporter may vary during the maturation of the cells in culture. Thus, we analyzed the transcriptional and protein time-course of VNUT and VGLUT1 expression in these cultures from days 1 to 10 in vitro. While VNUT mRNA expression could be detected from the first day of culture and it gradually increased over the following days (Figure 5B), VGLUT1 expression was not evident until day 4 in vitro, although it increased strongly on the following days (Figure 5C). The detection of both these vesicular transporters in western blots correlated well with their mRNA expression (Figure 5D), consistent with the maturation of the culture and the establishment of synaptic contacts by granule cells in vitro and the development of a functional synaptic machinery. Cerebellar extracts from P15 or adult mice were used as positive control of both transporters (Figure 5E).

\section{Presence and Distribution of VNUT in the Mouse Cerebellar Cortex}

The aforementioned results in primary cultures of cerebellar granule cells suggested the existence of different vesicular pools preferentially containing either VNUT or VGLUT1, with a few vesicles exhibiting both transporters. To assess whether this distribution reflects the situation in the mouse cerebellum, this tissue was immunostained with antibodies against both vesicular transporters. In slices of the postnatal day 15 (P15) mouse cerebellum, both vesicular transporters were located in the molecular and the granular layers of the cerebellar cortex (Figures 6A,B). While VGLUT1 was found in the axons and soma of granule cells located in the molecular and granular layers, respectively (Figure 6B), VNUT was also observed in the Purkinje layer surrounding the soma of Purkinje neurons (Figure 6B). Although these vesicular transporters exhibited distinct distributions, confocal images with orthogonal views showed a few examples of co-localization between VNUT and VGLUT1 in both the molecular (ML) and granular (GL) layers (Figures 6C,D).

The presence of VNUT early in primary cultures of granule cells obtained from P5 mice (Figures 1B, 5B,D) raised the question as to how such expression varied during cerebellar development. It is well known that the cortical layers of the cerebellum are not defined at P5 and that secondary proliferation niches containing granule cell precursors (GCPs) can be found (Altman, 1972; Espinosa and Luo, 2008). Moreover, at this time 
A
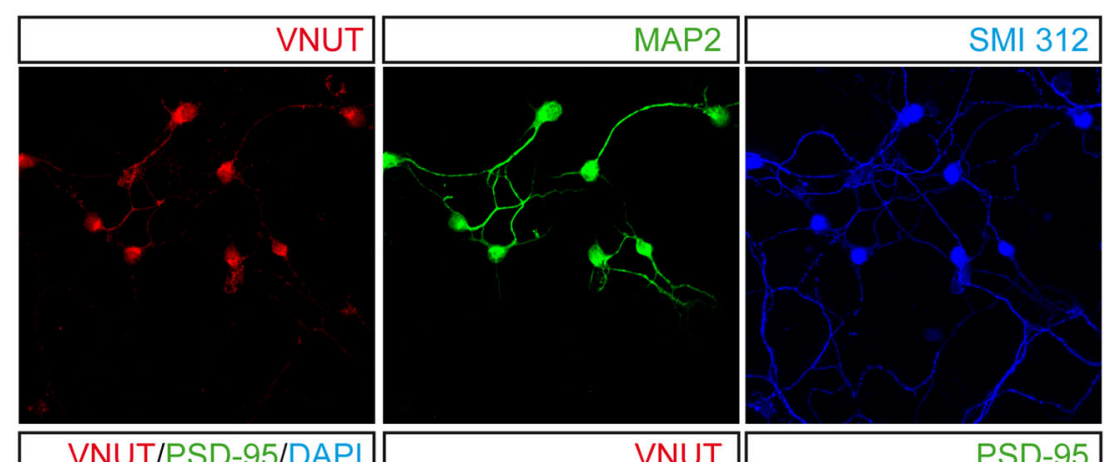

VNUT/MAP2/SMI 312

B
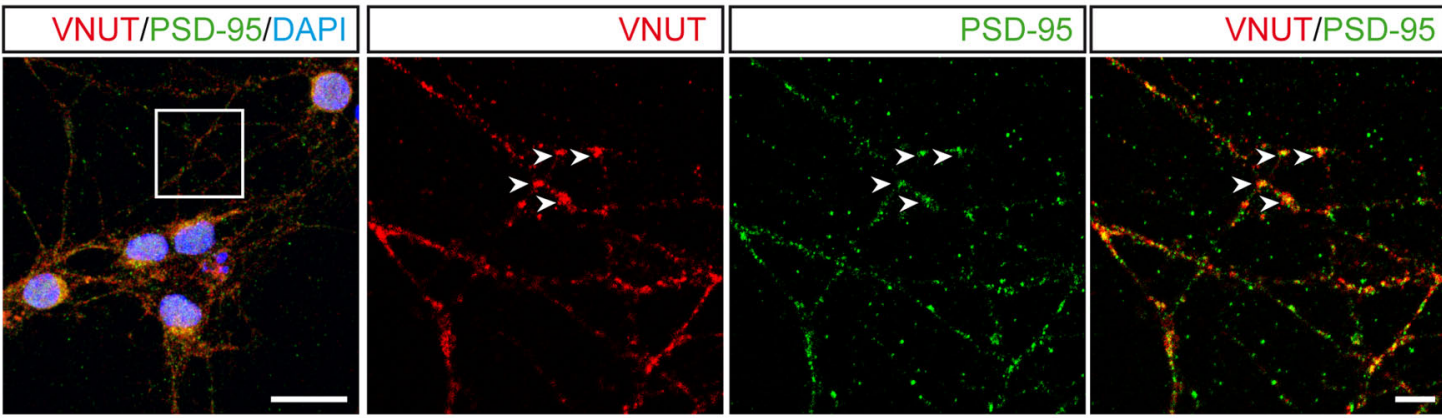

C
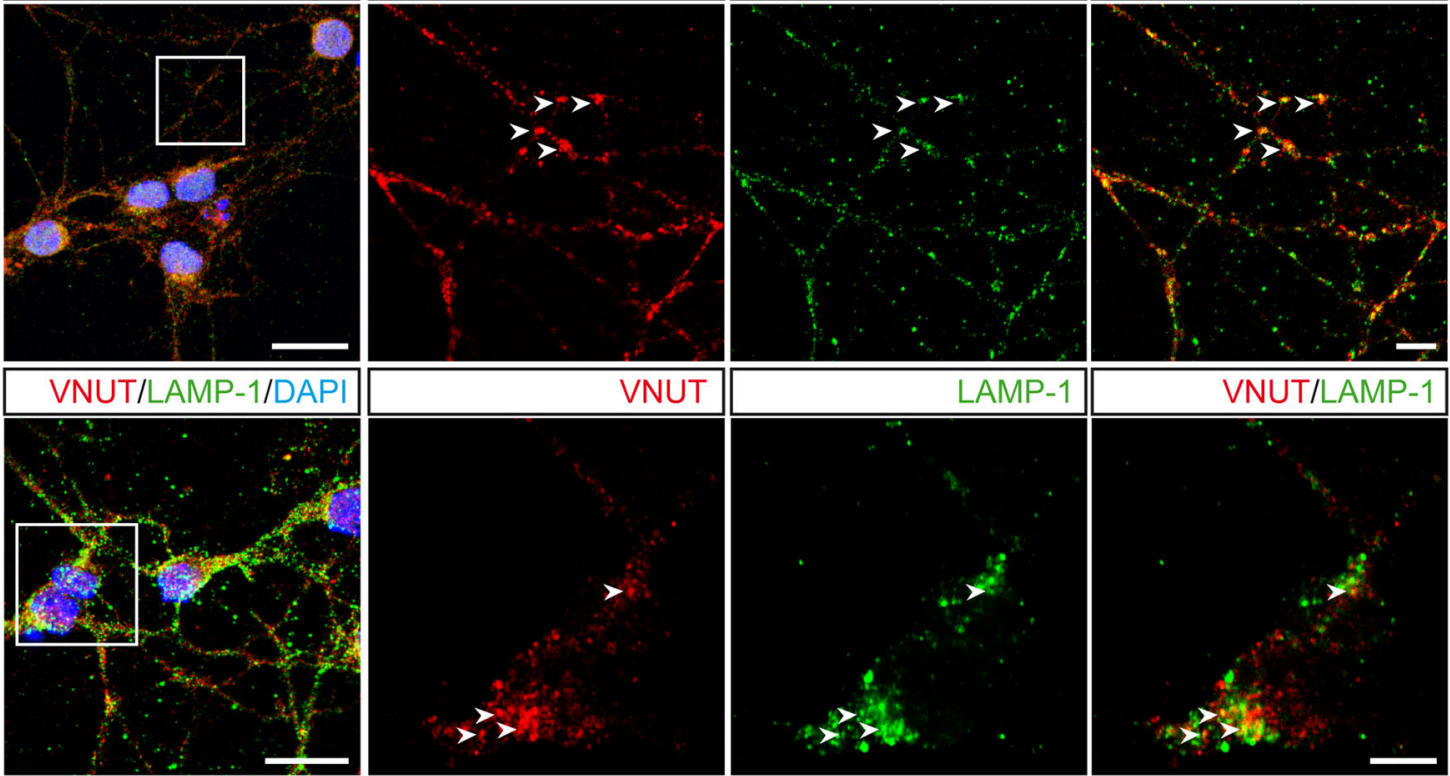

FIGURE 3 | Subcellular localization of VNUT in cerebellar granule cells. (A) Representative confocal images showing the immunofluorescence for VNUT (red), MAP2 (green) and SMI 312 (blue). Scale bar: $20 \mu \mathrm{m}$. (B) Confocal images of double immunofluorescence for VNUT (red) and PSD95 (green). Scale bar: $15 \mu \mathrm{m}$. Insets represents higher magnifications to show the co-localization (yellow) of VNUT (red) and PSD95 (green). Arrowheads indicated co-localized immunostaining for the two proteins. Scale bar: $5 \mu \mathrm{m}$. (C) Representative confocal images of double immunofluorescence for VNUT (red) and LAMP-1 (green). Scale bar: $15 \mu \mathrm{m}$. Insets represents higher magnifications to show co-localization (yellow) of VNUT (red) and LAMP-1 (green). The arrowheads indicate co-localization of the immunostaining for the two proteins. Scale bar: $5 \mu \mathrm{m}$

immature granule cells are migrating from the external granular layer (EGL) to the internal granular layer (IGL), where they will reach their final location (Altman and Bayer, 1997). At P5, VNUT staining in cerebellar slices was stronger and more widely distributed (Figures $\mathbf{7 A}, \mathbf{A}^{\prime}$ ) than at P15 stage (Figure 7E). To characterize the specific populations expressing VNUT during development, we used an antibody against Math1 to identify GCPs, a transcription factor of the bHLH (basic helix-loophelix) class that is essential for the proper development of cerebellar granule layer (Ben-Arie et al., 1997), and an antibody against the microtubule-associated protein doublecortin (DCX) to recognize neuroblasts and immature neurons (Figure 7). At P5, VNUT and Math1 co-localized in the cerebellum (Figures 7D, $\mathbf{D}^{\prime}$ ), confirming that GCPs express VNUT during their postnatal development. Moreover, in certain regions of the IGL, VNUT, Math1 and DCX co-localization was also observed (Figures 7D, $\mathbf{D}^{\prime}$ ). Hence, the onset of VNUT expression appears to commence early in cerebellar development, and it is expressed by neuronal progenitors like GCPs and immature neurons that have not fully differentiated. Alternatively, Math1 and DCX expression was weaker at P15 due to the development of the cerebellum (Figures 7E-H), although VNUT persisted at this stage and it was found in several cerebellar layers, yet mainly in the ML. These results correlate with our observations in vitro, whereby VNUT is expressed from the first day of cerebellar granule cell culture, when neurons are still immature, persisting once the neurons have matured and established functional synapses.

\section{DISCUSSION}

The present study confirms that the VNUT, is functionally expressed in primary cultures of cerebellar granule neurons, its 


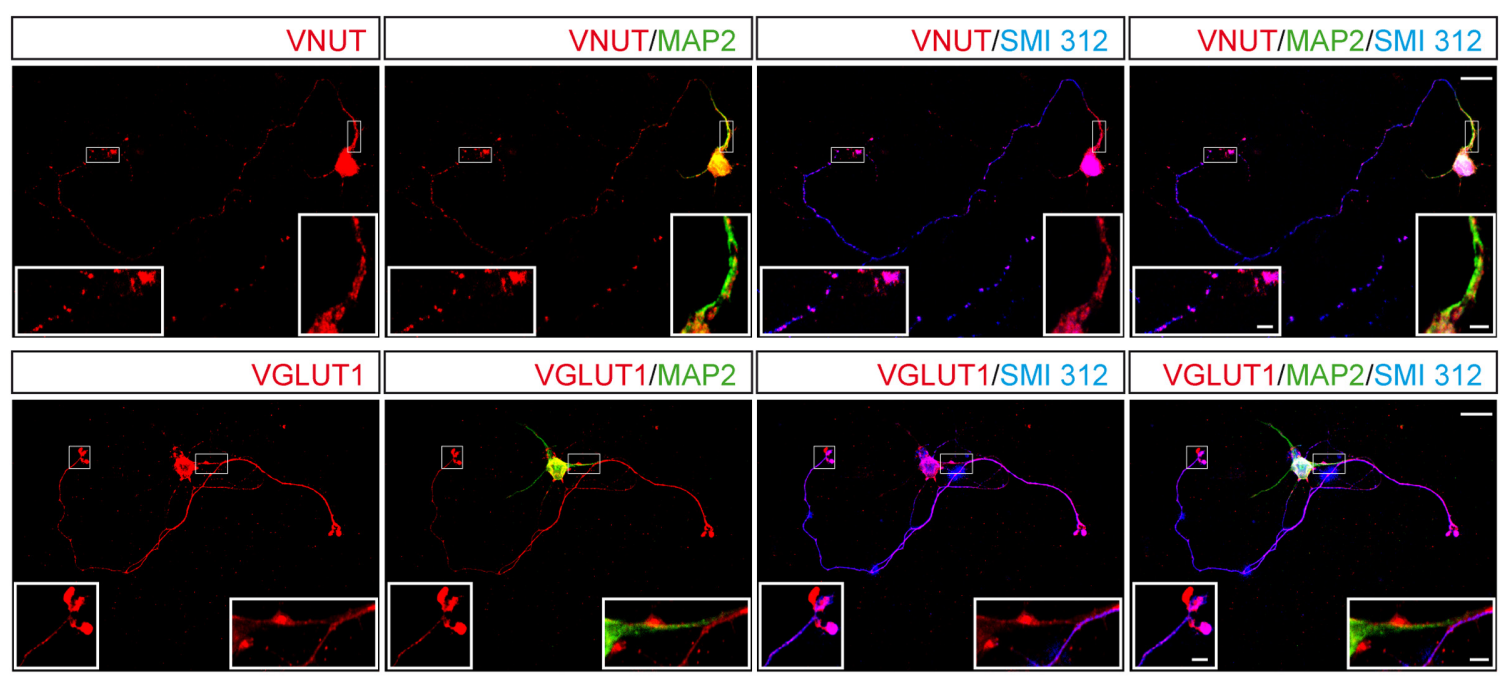

FIGURE 4 | Distribution of VNUT or VGLUT1 in a single cerebellar granule cell. Representative confocal images showing the immunostaining for MAP2 (green), SMI 312 (blue) and either VNUT (red, upper panels) or VGLUT1 (red, lower panels). Scale bar: $15 \mu \mathrm{m}$. The insets represent higher magnifications of the somatodendritic or axonal compartments. Scale bar: $2.5 \mu \mathrm{m}$.
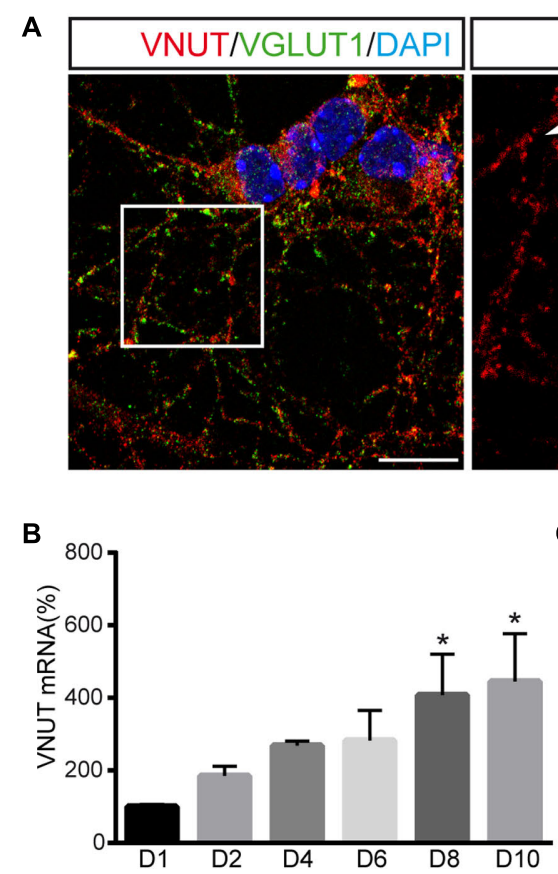
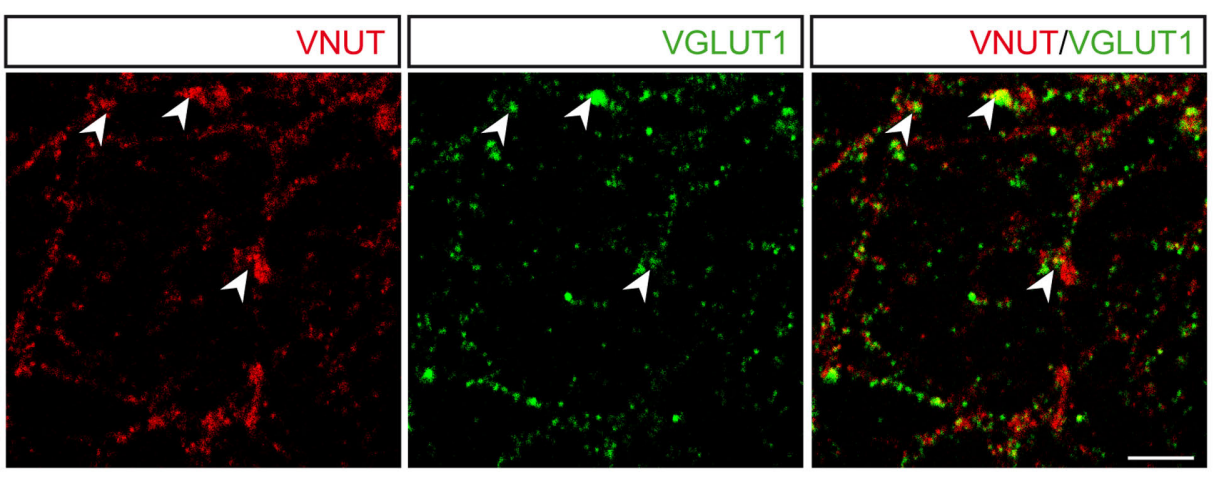

C

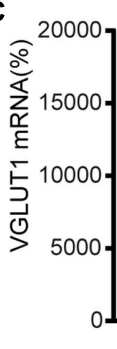

D

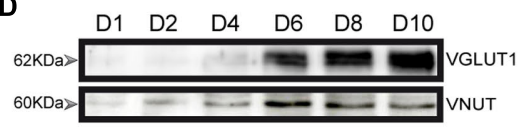

E

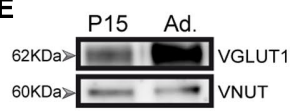

FIGURE 5 | Expression of VNUT and VGLUT1 in cerebellar granule cells. (A) Representative confocal images showing double immunofluorescence for VNUT (red) and VGLUT1 (green). The nuclei were counterstained with DAPI (blue). Scale bar: $12 \mu \mathrm{m}$. Right panels represent a higher magnification to show the immunostaining for each vesicular transporter. The arrowheads indicate co-localization of the immunoreactivity for VNUT and VGLUT1. Immunofluorescence was performed on day 7 in vitro. Scale bar: $5 \mu \mathrm{m}$. VNUT (B) and VGLUT1 (C) mRNA levels analyzed by GPCR of cerebellar granule cells after different days of the culture. The values represent the mean \pm SEM $\left(n=3:{ }^{*} p<0.05,{ }^{* *} p<0.01,{ }^{* * *} p<0.001\right.$, ANOVA with Dunnet test with respect to day 1). (D) Western blots of the total protein (10 $\left.\mu \mathrm{g}\right)$ in cell lysates after different times in culture. (E) Western blot of total protein extracts from cerebellum used as positive control of VNUT and VGLUT1 expression.

expression varying as the cell cultures mature in vitro and it is distributed in presynaptic and postsynaptic vesicles in these neurons. Moreover, we demonstrate that VNUT is expressed very early in the cerebellar granule neuronal lineage, both in vitro and in vivo. Together, these results imply that VNUT potentially contributes to the postnatal development of granule cells in the cerebellar cortex, a role that will be challenging to define. 

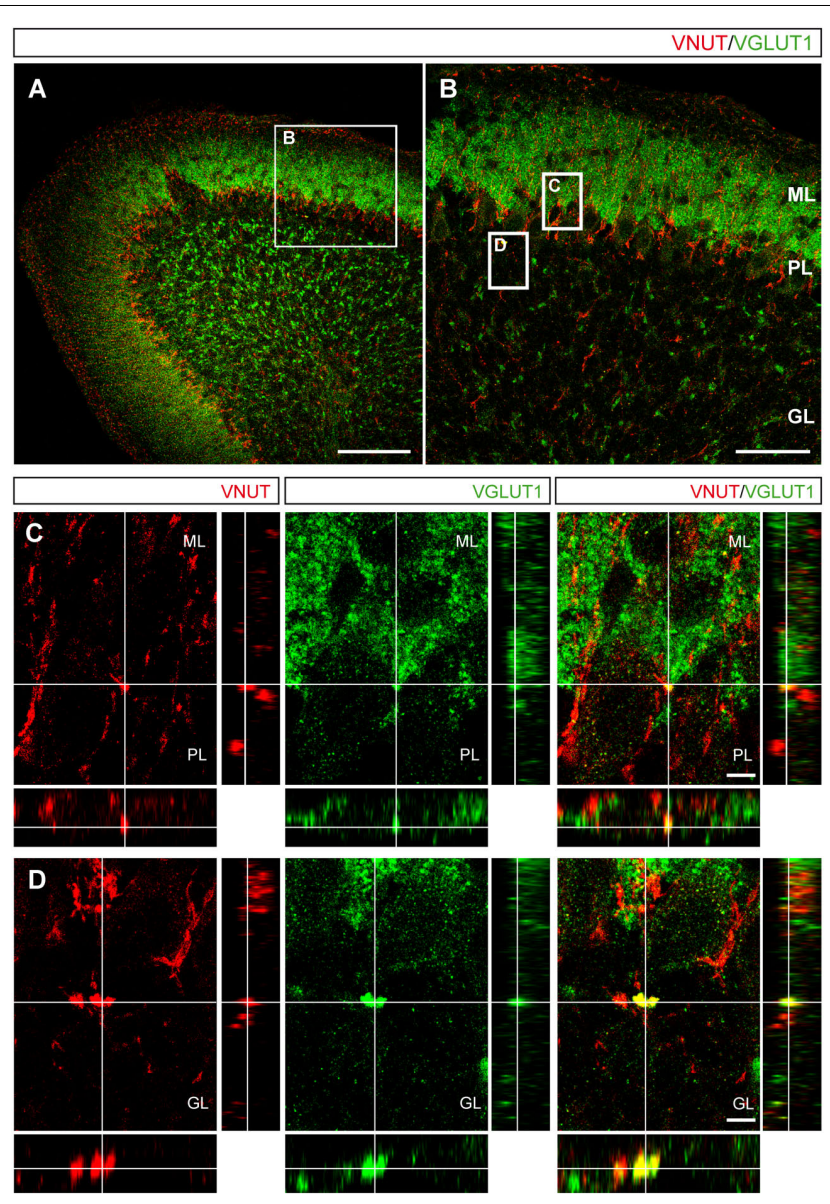

FIGURE 6 | Localization of VNUT and VGLUT1 in the mouse cerebellar cortex. (A) Representative micrograph of a section of the P15 cerebellum immunostained for VNUT (red) and VGLUT1 (green). Scale bar: $100 \mu \mathrm{m}$ (B) Higher magnification of the selected region in (A) showing the three cerebellar layers. Scale bar: $50 \mu \mathrm{m}$. The insets are shown in the lower panels. (C,D) Orthogonal sections. Selected z-scanning series of images showing double labeling for VNUT and VGLUT1, representing the three planes of view for one point, as indicated by the crossed dashed lines. Scale bar: $10 \mu \mathrm{m}$. ML, Molecular Layer; PL, Purkinje Layer; GL, Granular Layer.

Extracellular nucleotides play an essential role in cellular signaling, acting through purinergic receptors, and in neural tissues, extracellular ATP is involved in physiological processes like synaptic transmission, proliferation, differentiation or axonal elongation (Diaz-Hernandez et al., 2008; Gomez-Villafuertes et al., 2009; Diez-Zaera et al., 2011). In physio-pathological conditions including neuropathic pain, psychiatric disorders or epileptic seizures, enhanced $\mathrm{P} 2$ receptor expression has been reported, such as P2X4 or P2X7 (Tsuda et al., 2003; Beggs et al., 2012; Henshall et al., 2013; Sperlagh and Illes, 2014). Thus, the levels of extracellular nucleotides must be tightly controlled in order to only activate specific purinergic receptors when necessary. This tight regulation mainly focuses on controlling the release and the removal of nucleotides from the extracellular space. In terms of extracellular nucleotide removal, these compounds can be rapidly hydrolyzed to the last product adenosine, subsequently transported and incorporated to the cellular nucleotide pool (Rotllan and Miras Portugal, 1985; Miras-Portugal et al., 1986; Sen et al., 1998; Zimmermann et al., 2012; Gomez-Villafuertes et al., 2014; Pastor-Anglada and PerezTorras, 2015).

By contrast, the exocytotic release of ATP and other nucleotides depends on VNUT activity, which links the intraand extracellular steps of ATP signaling. Although its existence and kinetic parameters were described long ago (Bankston and Guidotti, 1996; Gualix et al., 1996, 1999a), not until recently was VNUT cloned (Sawada et al., 2008). VNUT is heterogeneously expressed in distinct cell subtypes and structures in the murine brain, being particularly abundant in cerebellar cortex (Larsson et al., 2012). However, little is known about its specific subcellular distribution and function within the complex cytoarchitecture of the cerebellum.

Among the different neuronal subtypes that make up the cerebellum, granule cells are the most abundant. Purinergic signaling seems to play an important role in these cells, since they not only strongly express different purinergic receptors but also, VNUT (Larsson et al., 2012). Primary cultures of granule cells represent a suitable model to understand basic neurobiological processes. For instance, depolarization of these glutamatergic neurons through the activation of $\mathrm{P} 2 \mathrm{X} 3$ or $\mathrm{P} 2 \mathrm{X} 7$ receptors can induce glutamate release (Leon et al., 2008). However, as mentioned previously, there is nothing known about the role of VNUT in this cell model, although the data presented here clarifies some relevant issues. First, VNUT appears to co-localize with the vesicular marker synaptophysin in these cells and in addition, granule cells appear to release ATP by exocytosis. As inhibiting VNUT reduces the net release of ATP, VNUT is clearly involved in the vesicular storage of ATP as indicated elsewhere (Gualix et al., 1999a,b; Sawada et al., 2008).

We previously showed that activation of $\mathrm{P} 2 \mathrm{X} 7$ receptors by ATP evokes the release of this nucleotide in neuroblastoma N2a cells (Gutierrez-Martin et al., 2011), and here we demonstrate a similar phenomenon occurs in cerebellar granule cells. Quinacrine loading highlighted the large number of acidic fluorescent vesicles that store ATP in cerebellar granule cells, and ATP stimulation induced an abrupt loss of fluorescence due to exocytosis. Hence, ATP appears to induce its own release in granule cells, an effect that could be mediated by P2X7 receptors since they require high ATP concentrations to be activated (Gutierrez-Martin et al., 2011). Depolarization induced by $\mathrm{KCl}$ also confirms the existence of a vesicular mechanism for ATP release, although it does not produce complete loss of quinacrine-loaded vesicles. This may indicate that not all the quinacrine-loaded vesicles belong to the ready releasable pool close to the plasma membrane or that these vesicles are not secretory ones. This latter possibility was confirmed by immunofluorescence assays with the lysosomal marker LAMP-1, whereby quinacrine-loaded vesicles that do not respond to the increase in intracellular calcium could be "conventional" lysosomes that accumulate high concentrations of ATP (Li et al., 2008). Moreover, VNUT does not fully co-localize with synaptophysin, indicating that the vesicular 

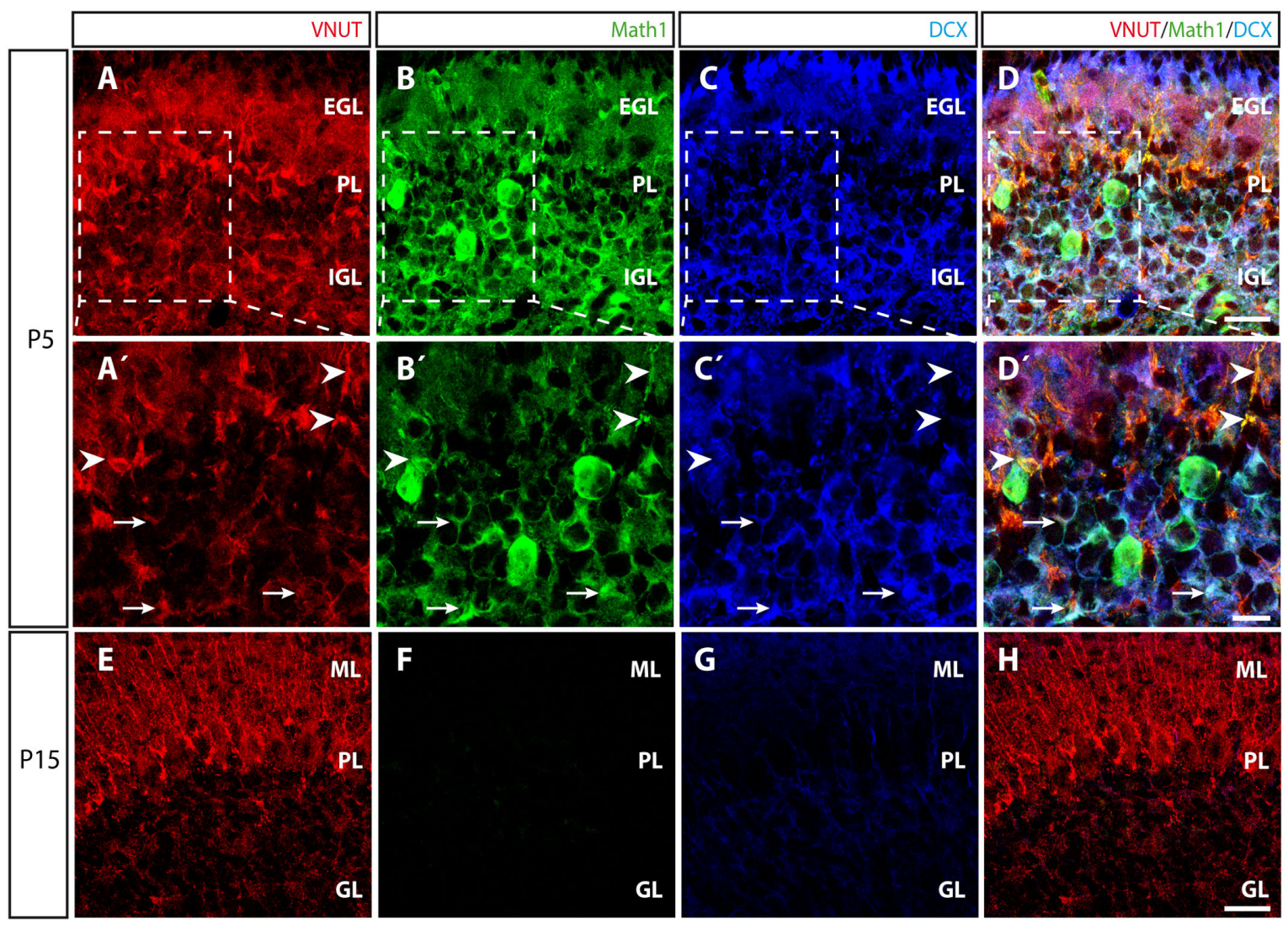

FIGURE 7 | Distribution of VNUT during the postnatal development of the cerebellar cortex. (A-D) Representative confocal images of P5 cerebellar sections showing triple immunofluorescence for VNUT (red), Math1 (a marker of committed GCPs) (green) and DCX (a marker of immature neurons) (blue), and the overlaid image. Scale bar: $20 \mu \mathrm{m}$. ( $\left.\mathbf{A}^{\prime}-\mathbf{D}^{\prime}\right)$ Higher magnification of the selected region at P5 in which the arrowheads indicate the co-localization of the immunoreactivity for VNUT and Math1. The arrows indicate the co-localization of VNUT, Math1 and DCX immunostaining. Scale bar: $10 \mu \mathrm{m}$. (E-H) Representative micrographs of P15 cerebellar sections showing triple immunofluorescence for VNUT (red), Math1 (green) and DCX, (blue) and the overlaid images. Scale bar: 20 $\mu$ m. EGL, External Granular Layer; PL, Purkinje Layer; IGL, Internal Granular Layer; ML, Molecular Layer; GL, Granular Layer.

transporter is present in non-synaptic vesicles. Indeed, VNUT has been identified in lysosomes of different cellular lineages (Shin et al., 2012; Oya et al., 2013; Cao et al., 2014), including sensory neurons (Jung et al., 2013). Lysosomes are best known for their role in protein degradation during autophagy and phagocytosis, yet they may also be involved in regulated exocytosis, acting as secretory vesicles (Blott and Griffiths, 2002; Li et al., 2008). Moreover, lysosomes can store large amounts of ATP and release it through exocytosis (Zhang et al., 2007; Pryazhnikov and Khiroug, 2008; Dou et al., 2012). In terms of cerebellar granule cells, the co-localization between VNUT and LAMP-1 confirmed the presence of this vesicular transporter in lysosomes, suggesting that these neurons can store ATP in lysosomes, and even release it from these vesicles by exocytosis.

Several studies of vesicular ATP release at central synapses suggest that ATP comes from a different pool of vesicles that is not synchronized either with GABA or glutamate release (for review see Pankratov et al., 2006). To assess whether cerebellar granule cells that release ATP and glutamate, and that express both VNUT and VGLUT1, also have a specific pool of ATP-containing vesicles, the distribution of both vesicular transporters was studied. When compared with the somatodendritic marker MAP2 and the neurofilament axonal marker SMI 312, VNUT was clearly present in both preand postsynaptic areas. By contrast, VGLUT1 was mainly seen to co-localize with the axonal marker and it was barely present in the somatodendritic regions. On the other hand, co-localization of VNUT and PSD-95 confirmed the transporter's presence in postsynaptic domains, suggesting that exocytosis of ATP could be bi-directional at synaptic contacts. Accordingly, the ATP released in the synaptic cleft can activate both pre- and postsynaptic purinergic receptors. At the presynaptic level, P2X receptor activation induces or enhances neurotransmitter release (Gu and MacDermott, 1997; Khakh and Henderson, 1998; Nakatsuka and Gu, 2001; Khakh et al., 2003; Rodrigues et al., 2005; Sperlagh et al., 2007; Khakh, 2009), whereas P2Y receptor activation mainly dampens neurotransmitter release (Rodrigues et al., 2005). Additionally, activation of postsynaptic P2X receptors may induce AMPA receptor internalization at the dendrites (Pougnet et al., 2014), modulating synaptic transmission. Presynaptic modulation by 
ATP could originate from different sources, the terminal itself and neighboring nerve terminals or astrocytes. Moreover, the postsynaptic location of VNUT in granule cells suggests an additional source of ATP through its release from dendrites. VNUT was previously found in postsynaptic dendrites of dentate gyrus and hippocampal CA1 neurons (Larsson et al., 2012). The possibility that dendritic spines might be able to release ATP indicates that they might modulate presynaptic release of neurotransmitters through a retrograde mechanism. Exocytotic release of ATP and glutamate from granule cells can occur simultaneously, although they may be stored in different vesicle pools, as reflected by the segregated distribution of VNUT and VGLUT1. Indeed, co-localization between these vesicular transporters was rare after 7 days in vitro, although the expression of VNUT and VGLUT1 increased as the granule cell cultures mature, consistent with the establishment of synaptic contacts that require the corresponding synaptic machinery. Nevertheless, VNUT expression by these cells was detected very early, from their first day in culture.

As the granule cells culture were obtained at an early postnatal developmental stage, it is possible that the expression of VNUT and VGLUT1is distinct in the native tissue. Thus, the distribution of both vesicular transporters was analyzed in sagittal sections of the cerebral cortex at P15 stage, when VGLUT expression increases significantly (Boulland et al., 2004). The two vesicular transporters exhibited a clear nonoverlapping distribution, with scarce co-localization, which was consistent with the results obtained in granule cell cultures. In fact, while the two transporters are located in both the molecular and granule layer of the cerebellar cortex, VNUTstaining was stronger in the molecular stratum. On the other hand, VNUT was also located around the soma of Purkinje cells, suggesting an important role of purinergic signaling in controlling GABAergic transmission (Casel et al., 2005). Indeed, it has already been demonstrated that P2X receptors can elicit $\mathrm{Ca}^{2+}$ responses in primary cultures of Purkinje cells (Mateo et al., 1998).

The evolution of VNUT expression in the mouse cerebellum was assessed from the immature postnatal P5-P15 stage. As the cerebellar layers are not well defined at P5 and granule cells are still migrating from the external to the internal granular layer, this appears to be a good model to correlate VNUT expression with that of the essential specific factors, Math1 and DCX. Math1 is a master gene that specifies the cerebellar granule neuron lineage and it is expressed in the committed GCPs (Ben-Arie et al., 1997; Srivastava et al., 2013), whereas DCX is a microtubule-associated protein that identifies neuronal precursors and immature neurons (Brown et al., 2003). In accordance with its early expression in vitro, VNUT was expressed abundantly at P5, and it co-localized with both Math1 and DCX, suggesting that it is expressed by GCPs and the immature neurons migrating from the external to the internal granular layer of the cerebellum. During the subsequent development of the cerebellum, committed granule cells become mature granule neurons between P5 and P15, as confirmed by the absence of Math1 and the dramatic reduction in DCX. Nevertheless, VNUT remains prominently expressed in the molecular and granule layer, highlighting the relevance of VNUT during the commitment and differentiation of cerebellar granule neurons.

There is now increasing evidence implicating VNUT in both physiological and pathological processes in neural tissues. For instance, VNUT helps regulate neuronal differentiation of neuroblastoma N2a cells (Menendez-Mendez et al., 2015) Moreover, during the development of glaucoma, there is a direct correlation between enhanced VNUT expression in the intern plexiform layers of the retina and an increase in extracellular ATP (Perez de Lara et al., 2015). More recently it was proposed that VNUT-dependent ATP release from spinal cord dorsal root neurons might originate neuropathic pain in mice (Masuda et al., 2016). Furthermore, clodronate was identified as a novel inhibitor of VNUT for the treatment of neuropathic and inflammatory pain, opening up new therapeutic possibilities for other pathologies (Kato et al., 2013, 2017).

In summary, we have characterized the subcellular localization and activity of VNUT during the maturation of cerebellar granule neurons in vitro. The correlation between these findings and the situation in the cerebellum in vivo raises exciting new questions that should be addressed in the near future.

\section{AUTHOR CONTRIBUTIONS}

AM-M designed, performed the majority of experiments and wrote the manuscript. JD-H designed and supervised the experiments. FO designed, performed the experiments and wrote the manuscript. JG designed and supervised the experiments. RG-V and MM-P was designed, supervised the experiments and wrote the manuscript.

\section{FUNDING}

This work was funded by the Spanish Ministerio de Economía y Competitividad (MINECO, BFU 2014-53654-P) and the "Red de Excelencia Consolider-Ingenio Spanish Ion Channel Initiative" (BFU2015-70067REDC); by the Comunidad de Madrid (BRADE-CM S2013/ICE-2958); UCM-Santander (PR26/16-18B-3) and by a Fundación Ramón Areces Grant (PR2018/16-02). AM-M is a recipient of a contract from the MINECO, BFU 2014-53654-P. FO acknowledges the Ramon y Cajal Program of the Spanish Ministry of Economy and Competitiveness (MEC: RYC-2013-13290).

\section{ACKNOWLEDGMENT}

The authors are grateful to Dr. Mark Sefton for his help in the preparation of this manuscript. 


\section{REFERENCES}

Altman, J. (1972). Postnatal development of the cerebellar cortex in the rat. I. The external germinal layer and the transitional molecular layer. J. Comp. Neurol. 145, 353-397. doi: 10.1002/cne.901450305

Altman, J., and Bayer, S. A. (1997). Development of the Cerebellar System in Relation to its Evolution, Structure and Function. Boca Raton, FL: CRC.

Bankston, L. A., and Guidotti, G. (1996). Characterization of ATP transport into chromaffin granule ghosts. Synergy of ATP and serotonin accumulation in chromaffin granule ghosts. J. Biol. Chem. 271, 17132-17138. doi: 10.1074/jbc. 271.29.17132

Baroja-Mazo, A., Barbera-Cremades, M., and Pelegrin, P. (2013). The participation of plasma membrane hemichannels to purinergic signaling. Biochim. Biophys. Acta 1828, 79-93. doi: 10.1016/j.bbamem.2012.01.002

Beggs, S., Trang, T., and Salter, M. W. (2012). P2X4R+ microglia drive neuropathic pain. Nat. Neurosci. 15, 1068-1073. doi: 10.1038/nn.3155

Ben-Arie, N., Bellen, H. J., Armstrong, D. L., McCall, A. E., Gordadze, P. R., Guo, Q., et al. (1997). Math1 is essential for genesis of cerebellar granule neurons. Nature 390, 169-172. doi: 10.1038/36579

Blott, E. J., and Griffiths, G. M. (2002). Secretory lysosomes. Nat. Rev. Mol. Cell Biol. 3, 122-131. doi: 10.1038/nrm732

Boulland, J. L., Qureshi, T., Seal, R. P., Rafiki, A., Gundersen, V., Bergersen, L. H., et al. (2004). Expression of the vesicular glutamate transporters during development indicates the widespread corelease of multiple neurotransmitters. J. Comp. Neurol. 480, 264-280. doi: 10.1002/cne.20354

Brown, J. P., Couillard-Despres, S., Cooper-Kuhn, C. M., Winkler, J., Aigner, L., and Kuhn, H. G. (2003). Transient expression of doublecortin during adult neurogenesis. J. Comp. Neurol. 467, 1-10. doi: 10.1002/cne.10874

Burnstock, G. (1976). Do some nerve cells release more than one transmitter? Neuroscience 1, 239-248.

Burnstock, G. (2004). Cotransmission. Curr. Opin. Pharmacol. 4, 47-52. doi: 10.1016/j.coph.2003.08.001

Burnstock, G. (2006). Historical review: ATP as a neurotransmitter. Trends Pharmacol. Sci. 27, 166-176. doi: 10.1016/j.tips.2006.01.005

Burnstock, G. (2013). Introduction to purinergic signalling in the brain. Adv. Exp. Med. Biol. 986, 1-12. doi: 10.1007/978-94-007-4719-7_1

Cao, Q., Zhao, K., Zhong, X. Z., Zou, Y., Yu, H., Huang, P., et al. (2014). SLC17A9 protein functions as a lysosomal ATP transporter and regulates cell viability. J. Biol. Chem. 289, 23189-23199. doi: 10.1074/jbc.M114.567107

Casel, D., Brockhaus, J., and Deitmer, J. W. (2005). Enhancement of spontaneous synaptic activity in rat Purkinje neurones by ATP during development. J. Physiol. 568(Pt 1), 111-122. doi: 10.1113/jphysiol.2005.091371

Cerminara, N. L., Lang, E. J., Sillitoe, R. V., and Apps, R. (2015). Redefining the cerebellar cortex as an assembly of non-uniform Purkinje cell microcircuits. Nat. Rev. Neurosci. 16, 79-93. doi: 10.1038/nrn3886

Diaz-Hernandez, M., del Puerto, A., Diaz-Hernandez, J. I., Diez-Zaera, M., Lucas, J. J., Garrido, J. J., et al. (2008). Inhibition of the ATP-gated P2X7 receptor promotes axonal growth and branching in cultured hippocampal neurons. J. Cell Sci. 121(Pt 22), 3717-3728. doi: 10.1242/jcs.034082

Diez-Zaera, M., Diaz-Hernandez, J. I., Hernandez-Alvarez, E., Zimmermann, H., Diaz-Hernandez, M., and Miras-Portugal, M. T. (2011). Tissue-nonspecific alkaline phosphatase promotes axonal growth of hippocampal neurons. Mol. Biol. Cell 22, 1014-1024. doi: 10.1091/mbc.E10-09-0740

Dou, Y., Wu, H. J., Li, H. Q., Qin, S., Wang, Y. E., Li, J., et al. (2012). Microglial migration mediated by ATP-induced ATP release from lysosomes. Cell Res. 22, 1022-1033. doi: 10.1038/cr.2012.10

Erickson, J. D., Eiden, L. E., and Hoffman, B. J. (1992). Expression cloning of a reserpine-sensitive vesicular monoamine transporter. Proc. Natl. Acad. Sci. U.S.A. 89, 10993-10997. doi: 10.1073/pnas.89.22.10993

Espinosa, J. S., and Luo, L. (2008). Timing neurogenesis and differentiation: insights from quantitative clonal analyses of cerebellar granule cells. J. Neurosci. 28, 2301-2312. doi: 10.1523/JNEUROSCI.5157-07.2008

Estevez-Herrera, J., Dominguez, N., Pardo, M. R., Gonzalez-Santana, A., Westhead, E. W., Borges, R., et al. (2016). ATP: The crucial component of secretory vesicles. Proc. Natl. Acad. Sci. U.S.A. 113, E4098-E4106. doi: 10.1073/ pnas. 1600690113

Gomez-Villafuertes, R., del Puerto, A., Diaz-Hernandez, M., Bustillo, D., DiazHernandez, J. I., Huerta, P. G., et al. (2009). Ca2+/calmodulin-dependent kinase II signalling cascade mediates P2X7 receptor-dependent inhibition of neuritogenesis in neuroblastoma cells. FEBS J. 276, 5307-5325. doi: 10.1111/ j.1742-4658.2009.07228.x

Gomez-Villafuertes, R., Pintor, J., Miras-Portugal, M. T., and Gualix, J. (2014). Ectonucleotide pyrophosphatase/phosphodiesterase activity in Neuro2a neuroblastoma cells: changes in expression associated with neuronal differentiation. J. Neurochem. 131, 290-302. doi: 10.1111/jnc.12794

Gu, J. G., and MacDermott, A. B. (1997). Activation of ATP P2X receptors elicits glutamate release from sensory neuron synapses. Nature 389, 749-753. doi: $10.1038 / 39639$

Gualix, J., Abal, M., Pintor, J., Garcia-Carmona, F., and Miras-Portugal, M. T. (1996). Nucleotide vesicular transporter of bovine chromaffin granules. Evidence for a mnemonic regulation. J. Biol. Chem. 271, 1957-1965. doi: 10.1074/jbc.271.4.1957

Gualix, J., Alvarez, A. M., Pintor, J., and Miras-Portugal, M. T. (1999a). Studies of chromaffin granule functioning by flow cytometry: transport of fluorescent epsilon-ATP and granular size increase induced by ATP. Receptors Channels 6, 449-461.

Gualix, J., Pintor, J., and Miras-Portugal, M. T. (1999b). Characterization of nucleotide transport into rat brain synaptic vesicles. J. Neurochem. 73, 1098-1104.

Gutierrez-Martin, Y., Bustillo, D., Gomez-Villafuertes, R., Sanchez-Nogueiro, J., Torregrosa-Hetland, C., Binz, T., et al. (2011). P2X7 receptors trigger ATP exocytosis and modify secretory vesicle dynamics in neuroblastoma cells. J. Biol. Chem. 286, 11370-11381. doi: 10.1074/jbc.M110.139410

Haanes, K. A., and Novak, I. (2010). ATP storage and uptake by isolated pancreatic zymogen granules. Biochem. J. 429, 303-311. doi: 10.1042/BJ200 91337

Hallberg, O. E., Bogen, I. L., Reistad, T., Haug, K. H., Wright, M. S., Fonnum, F., et al. (2006). Differential development of vesicular glutamate transporters in brain: an in vitro study of cerebellar granule cells. Neurochem. Int. 48, 579-585. doi: 10.1016/j.neuint.2005.12.027

Henshall, D. C., Diaz-Hernandez, M., Miras-Portugal, M. T., and Engel, T. (2013). $\mathrm{P} 2 \mathrm{X}$ receptors as targets for the treatment of status epilepticus. Front. Cell Neurosci. 7:237. doi: 10.3389/fncel.2013.00237

Hervas, C., Perez-Sen, R., and Miras-Portugal, M. T. (2003). Coexpression of functional P2X and P2Y nucleotide receptors in single cerebellar granule cells. J. Neurosci. Res. 73, 384-399. doi: 10.1002/jnr.10676

Hervas, C., Perez-Sen, R., and Miras-Portugal, M. T. (2005). Presence of diverse functional P2X receptors in rat cerebellar synaptic terminals. Biochem. Pharmacol. 70, 770-785. doi: 10.1016/j.bcp.2005.05.033

Jung, J., Shin, Y. H., Konishi, H., Lee, S. J., and Kiyama, H. (2013). Possible ATP release through lysosomal exocytosis from primary sensory neurons. Biochem. Biophys. Res. Commun. 430, 488-493. doi: 10.1016/j.bbrc.2012.12.009

Juranek, J. K., Mukherjee, K., Siddiqui, T. J., Kaplan, B. J., Li, J. Y., AhnertHilger, G., et al. (2013). Active zone protein expression changes at the key stages of cerebellar cortex neurogenesis in the rat. Acta Histochem. 115, 616-625. doi: 10.1016/j.acthis.2013.01.003

Kato, Y., Hiasa, M., Ichikawa, R., Hasuzawa, N., Kadowaki, A., Iwatsuki, K., et al. (2017). Identification of a vesicular ATP release inhibitor for the treatment of neuropathic and inflammatory pain. Proc. Natl. Acad. Sci. U.S.A. doi: 10.1073/ pnas.1704847114 [Epub ahead of print].

Kato, Y., Omote, H., and Miyaji, T. (2013). Inhibitors of ATP release inhibit vesicular nucleotide transporter. Biol. Pharm. Bull. 36, 1688-1691. doi: 10.1248/ bpb.b13-00544

Khakh, B. S. (2009). ATP-gated P2X receptors on excitatory nerve terminals onto interneurons initiate a form of asynchronous glutamate release. Neuropharmacology 56, 216-222. doi: 10.1016/j.neuropharm.2008.06.011

Khakh, B. S., Gittermann, D., Cockayne, D. A., and Jones, A. (2003). ATP modulation of excitatory synapses onto interneurons. J. Neurosci. 23, 7426-7437.

Khakh, B. S., and Henderson, G. (1998). ATP receptor-mediated enhancement of fast excitatory neurotransmitter release in the brain. Mol. Pharmacol. 54, 372-378.

Larsson, M., Sawada, K., Morland, C., Hiasa, M., Ormel, L., Moriyama, Y., et al. (2012). Functional and anatomical identification of a vesicular transporter mediating neuronal ATP release. Cereb. Cortex 22, 1203-1214. doi: 10.1093/ cercor/bhr203 
Leon, D., Hervas, C., and Miras-Portugal, M. T. (2006). P2Y1 and P2X7 receptors induce calcium/calmodulin-dependent protein kinase II phosphorylation in cerebellar granule neurons. Eur. J. Neurosci. 23, 2999-3013. doi: 10.1111/j.14609568.2006.04832.x

Leon, D., Sanchez-Nogueiro, J., Marin-Garcia, P., and Miras-Portugal, M. A. (2008). Glutamate release and synapsin-I phosphorylation induced by P2X7 receptors activation in cerebellar granule neurons. Neurochem. Int. 52, 1148-1159. doi: 10.1016/j.neuint.2007.12.004

Levesque, S. A., Lavoie, E. G., Lecka, J., Bigonnesse, F., and Sevigny, J. (2007). Specificity of the ecto-ATPase inhibitor ARL 67156 on human and mouse ectonucleotidases. Br. J. Pharmacol. 152, 141-150. doi: 10.1038/sj.bjp.0707361

Li, D., Ropert, N., Koulakoff, A., Giaume, C., and Oheim, M. (2008). Lysosomes are the major vesicular compartment undergoing $\mathrm{Ca} 2+-$ regulated exocytosis from cortical astrocytes. J. Neurosci. 28, 7648-7658. doi: 10.1523/JNEUROSCI.074408.2008

Li, H., and Harlow, M. L. (2014). Individual synaptic vesicles from the electroplaque of Torpedo californica, a classic cholinergic synapse, also contain transporters for glutamate and ATP. Physiol. Rep. 2:e00206. doi: 10.1002/ phy2.206

Liu, J., Liu, W., and Yang, J. (2016). ATP-containing vesicles in stria vascular marginal cell cytoplasms in neonatal rat cochlea are lysosomes. Sci. Rep. 6:20903. doi: 10.1038/srep20903

Loiola, E. C., and Ventura, A. L. (2011). Release of ATP from avian Muller glia cells in culture. Neurochem. Int. 58, 414-422. doi: 10.1016/j.neuint.2010.12.019

Masuda, T., Ozono, Y., Mikuriya, S., Kohro, Y., Tozaki-Saitoh, H., Iwatsuki, K., et al. (2016). Dorsal horn neurons release extracellular ATP in a VNUTdependent manner that underlies neuropathic pain. Nat. Commun. 7:12529. doi: $10.1038 /$ ncomms12529

Mateo, J., Garcia-Lecea, M., Miras-Portugal, M. T., and Castro, E. (1998). Ca2+ signals mediated by P2X-type purinoceptors in cultured cerebellar Purkinje cells. J. Neurosci. 18, 1704-1712.

Menendez-Mendez, A., Diaz-Hernandez, J. I., and Miras-Portugal, M. T. (2015). The vesicular nucleotide transporter (VNUT) is involved in the extracellular ATP effect on neuronal differentiation. Purinergic Signal. 11, 239-249. doi: 10.1007/s11302-015-9449-4

Miras-Portugal, M. T., Gomez-Villafuertes, R., Gualix, J., Diaz-Hernandez, J. I., Artalejo, A. R., Ortega, F., et al. (2016). Nucleotides in neuroregeneration and neuroprotection. Neuropharmacology 104, 243-254. doi: 10.1016/j. neuropharm.2015.09.002

Miras-Portugal, M. T., Torres, M., Rotllan, P., and Aunis, D. (1986). Adenosine transport in bovine chromaffin cells in culture. J. Biol. Chem. 261, 1712-1719.

Morente, V., Perez-Sen, R., Ortega, F., Huerta-Cepas, J., Delicado, E. G., and MirasPortugal, M. T. (2014). Neuroprotection elicited by P2Y13 receptors against genotoxic stress by inducing DUSP2 expression and MAPK signaling recovery. Biochim. Biophys. Acta 1843, 1886-1898. doi: 10.1016/j.bbamcr.2014.05.004

Mundy, W. R., Robinette, B., Radio, N. M., and Freudenrich, T. M. (2008). Protein biomarkers associated with growth and synaptogenesis in a cell culture model of neuronal development. Toxicology 249, 220-229. doi: 10.1016/j.tox.2008.05.012

Nakatsuka, T., and Gu, J. G. (2001). ATP P2X receptor-mediated enhancement of glutamate release and evoked EPSCs in dorsal horn neurons of the rat spinal cord. J. Neurosci. 21, 6522-6531.

Orriss, I. R., Knight, G. E., Utting, J. C., Taylor, S. E., Burnstock, G., and Arnett, T. R. (2009). Hypoxia stimulates vesicular ATP release from rat osteoblasts. J. Cell. Physiol. 220, 155-162. doi: 10.1002/jcp.21745

Ortega, F., Perez-Sen, R., Delicado, E. G., and Miras-Portugal, M. T. (2009). P2X7 nucleotide receptor is coupled to GSK-3 inhibition and neuroprotection in cerebellar granule neurons. Neurotox. Res. 15, 193-204. doi: 10.1007/s12640009-9020-6

Ortega, F., Perez-Sen, R., Delicado, E. G., and Teresa Miras-Portugal, M. (2011). ERK1/2 activation is involved in the neuroprotective action of P2Y13 and P2X7 receptors against glutamate excitotoxicity in cerebellar granule neurons. Neuropharmacology 61, 1210-1221. doi: 10.1016/j.neuropharm.2011.07.010

Ortega, F., Perez-Sen, R., Morente, V., Delicado, E. G., and Miras-Portugal, M. T. (2010). P2X7, NMDA and BDNF receptors converge on GSK3 phosphorylation and cooperate to promote survival in cerebellar granule neurons. Cell Mol. Life Sci. 67, 1723-1733. doi: 10.1007/s00018-010-0278-x

Oya, M., Kitaguchi, T., Yanagihara, Y., Numano, R., Kakeyama, M., Ikematsu, K., et al. (2013). Vesicular nucleotide transporter is involved in ATP storage of secretory lysosomes in astrocytes. Biochem. Biophys. Res. Commun. 438, 145-151. doi: 10.1016/j.bbrc.2013.07.043

Pankratov, Y., Lalo, U., Verkhratsky, A., and North, R. A. (2006). Vesicular release of ATP at central synapses. Pflugers Arch. 452, 589-597. doi: 10.1007/s00424006-0061-x

Pastor-Anglada, M., and Perez-Torras, S. (2015). Nucleoside transporter proteins as biomarkers of drug responsiveness and drug targets. Front. Pharmacol. 6:13. doi: 10.3389/fphar.2015.00013

Perez de Lara, M. J., Guzman-Aranguez, A., de la Villa, P., Diaz-Hernandez, J. I, Miras-Portugal, M. T., and Pintor, J. (2015). Increased levels of extracellular ATP in glaucomatous retinas: possible role of the vesicular nucleotide transporter during the development of the pathology. Mol. Vis. 21, 1060-1070.

Pons, S., Trejo, J. L., Martinez-Morales, J. R., and Marti, E. (2001). Vitronectin regulates Sonic hedgehog activity during cerebellum development through CREB phosphorylation. Development 128, 1481-1492.

Pougnet, J. T., Toulme, E., Martinez, A., Choquet, D., Hosy, E., and BoueGrabot, E. (2014). ATP P2X receptors downregulate AMPA receptor trafficking and postsynaptic efficacy in hippocampal neurons. Neuron 83, 417-430. doi: 10.1016/j.neuron.2014.06.005

Pryazhnikov, E., and Khiroug, L. (2008). Sub-micromolar increase in $[\mathrm{Ca}(2+)](\mathrm{i})$ triggers delayed exocytosis of ATP in cultured astrocytes. Glia 56, 38-49. doi: 10.1002/glia.20590

Ramón y Cajal, S. (1889). Sobre las fibras nerviosas de la capa granulosa del cerebelo. Rev. Trim. Histol. Norm. Patol. 1, 107-118.

Ramón y Cajal, S. (1904). Textura del Sistema Nervioso del Hombre y de Los Vertebrados: Estudios Sobre el Plan Estructural y Composición Histológical de Los Centros Nerviosos Adicionados de Consideraciones Fisiológicas Fundadas en Los Nuevos Descubrimientos. Madrid: Moya.

Ramón y Cajal, S. (1995). Histology of the Nervous System of Man and Vertebrates. New York, NY: Oxford University Press.

Rodrigues, R. J., Almeida, T., Richardson, P. J., Oliveira, C. R., and Cunha, R. A. (2005). Dual presynaptic control by ATP of glutamate release via facilitatory $\mathrm{P} 2 \mathrm{X} 1, \mathrm{P} 2 \mathrm{X} 2 / 3$, and $\mathrm{P} 2 \mathrm{X} 3$ and inhibitory P2Y1, P2Y2, and/or P2Y4 receptors in the rat hippocampus. J. Neurosci. 25, 6286-6295. doi: 10.1523/JNEUROSCI. 0628-05.2005

Rotllan, P., and Miras Portugal, M. T. (1985). Adenosine kinase from bovine adrenal medulla. Eur. J. Biochem. 151, 365-371. doi: 10.1111/j.1432-1033.1985. tb09110.x

Sanchez-Nogueiro, J., Marin-Garcia, P., Bustillo, D., Olivos-Ore, L. A., MirasPortugal, M. T., and Artalejo, A. R. (2014). Subcellular distribution and early signalling events of $\mathrm{P} 2 \mathrm{X} 7$ receptors from mouse cerebellar granule neurons. Eur. J. Pharmacol. 744, 190-202. doi: 10.1016/j.ejphar.2014.10.036

Sanchez-Nogueiro, J., Marin-Garcia, P., Leon, D., Leon-Otegui, M., Salas, E., Gomez-Villafuertes, R., et al. (2009). Axodendritic fibres of mouse cerebellar granule neurons exhibit a diversity of functional P2X receptors. Neurochem. Int. 55, 671-682. doi: 10.1016/j.neuint.2009.06.009

Sanz, J. M., Vendite, D., Fernandez, M., Andres, A., and Ros, M. (1996). Adenosine A1 receptors in cultured cerebellar granule cells: role of endogenous adenosine. J. Neurochem. 67, 1469-1477. doi: 10.1046/j.1471-4159.1996.67041469.x

Sawada, K., Echigo, N., Juge, N., Miyaji, T., Otsuka, M., Omote, H., et al. (2008). Identification of a vesicular nucleotide transporter. Proc. Natl. Acad. Sci. U.S.A. 105, 5683-5686. doi: 10.1073/pnas.0800141105

Sen, R. P., Delicado, E. G., Alvarez, A., Brocklebank, A. M., Wiley, J. S., and Miras-Portugal, M. T. (1998). Flow cytometric studies of nucleoside transport regulation in single chromaffin cells. FEBS Lett. 422, 368-372. doi: 10.1016/ S0014-5793(98)00047-7

Shin, Y. H., Lee, S. J., and Jung, J. (2012). Secretion of ATP from Schwann cells through lysosomal exocytosis during Wallerian degeneration. Biochem. Biophys. Res. Commun. 429, 163-167. doi: 10.1016/j.bbrc.2012. 10.121

Sperlagh, B., Heinrich, A., and Csolle, C. (2007). P2 receptor-mediated modulation of neurotransmitter release-an update. Purinergic Signal. 3, 269-284. doi: 10.1007/s11302-007-9080-0

Sperlagh, B., and Illes, P. (2014). P2X7 receptor: an emerging target in central nervous system diseases. Trends Pharmacol. Sci. 35, 537-547. doi: 10.1016/j.tips. 2014.08.002

Srivastava, R., Kumar, M., Peineau, S., Csaba, Z., Mani, S., Gressens, P., et al. (2013). Conditional induction of Math1 specifies embryonic stem cells to 
cerebellar granule neuron lineage and promotes differentiation into mature granule neurons. Stem Cells 31, 652-665. doi: 10.1002/stem.1295

Tsuda, M., Shigemoto-Mogami, Y., Koizumi, S., Mizokoshi, A., Kohsaka, S., Salter, M. W., et al. (2003). P2X4 receptors induced in spinal microglia gate tactile allodynia after nerve injury. Nature 424, 778-783. doi: 10.1038/nature 01786

Volknandt, W., and Zimmermann, H. (1986). Acetylcholine, ATP, and proteoglycan are common to synaptic vesicles isolated from the electric organs of electric eel and electric catfish as well as from rat diaphragm. J. Neurochem. 47, 1449-1462. doi: 10.1111/j.1471-4159.1986.tb0 0778.x

Winkler, H., and Westhead, E. (1980). The molecular organization of adrenal chromaffin granules. Neuroscience 5, 1803-1823. doi: 10.1016/0306-4522(80) 90031-7

Zhang, Z., Chen, G., Zhou, W., Song, A., Xu, T., Luo, Q., et al. (2007). Regulated ATP release from astrocytes through lysosome exocytosis. Nat. Cell Biol. 9, 945-953. doi: $10.1038 /$ ncb1620
Zimmermann, H., Zebisch, M., and Strater, N. (2012). Cellular function and molecular structure of ecto-nucleotidases. Purinergic Signal. 8, 437-502. doi: 10.1007/s11302-012-9309-4

Conflict of Interest Statement: The authors declare that the research was conducted in the absence of any commercial or financial relationships that could be construed as a potential conflict of interest.

The reviewer MP-A and handling editor declared their shared affiliation.

Copyright () 2017 Menéndez-Méndez, Díaz-Hernández, Ortega, Gualix, GómezVillafuertes and Miras-Portugal. This is an open-access article distributed under the terms of the Creative Commons Attribution License (CC BY). The use, distribution or reproduction in other forums is permitted, provided the original author(s) or licensor are credited and that the original publication in this journal is cited, in accordance with accepted academic practice. No use, distribution or reproduction is permitted which does not comply with these terms. 